\title{
Willingness To Pay Petani terhadap Pelaksanaan Asuransi Usaha Tani Padi (AUTP) (Studi Kasus Subak Cepik Desa Tajen Kecamatan Penebel Kabupaten Tabanan)
}

\author{
NI NENGAH SURNING, I GUSTI AGUNG AYU AMBARAWATI, \\ I NYOMAN GEDE USTRIYANA \\ Program Studi Agribisnis Fakultas Pertanian Universitas Udayana \\ Jalan PB Sudirman Denpasar 80232 \\ E-mail : nengahunink@yahoo.co.id \\ annie.ambarawati@gmail.com
}

\begin{abstract}
Farmer's Willingness to Pay to the Implementation of Rice Farming Insurance (Case Study of Subak Cepik Tajen Village, District of Penebel Tabanan Regency)
\end{abstract}

Asuransi Usaha Tani Padi (AUTP) is one of program by Indonesia Government to protect the farmers if there is a risk happen and causes the farmer loss their results during paddy farming. Subak Cepik is one of subak join AUTP since 2015 and having the most claims in Bali Province. The purpose of this research is to find out about willingness to pay by the farmers or we can understanding it as farmer's ability to pay premiums AUTP and to know the constraints that occurs in the implementation of AUTP for the Subak Cepik farmers and PT Jasindo. This research is using descriptive quantitative and descriptive qualitative method and used 40 sample of farmers. The data analyzed using Contingent Valuation Method (CVM). The result of this research shows that farmer's willingness to pay is Rp 30,853/ha/planting season. The amount is smaller than the current premium of Rp 36,000/ha/planting season.. Besides, this research also shows obstacles in the implementation of AUTP for farmers that is from the process of socialization AUTP, premium payment process and claims fund that is still lack for farming needs and constraints from the PT Jasindo including the process of socialization and registration process of AUTP participants. Subak Cepik farmers still want government subsidies and want to improve the service of AUTP. Result from this research suggest there is a need to synergize PT Jasindo and the farmers need for synergy. Then, the government also expected to set the AUTP premium in accordance with the capability of farmers.

Keywords: rice farming insurance, willingness to pay, contingent valuation model 


\section{Pendahuluan}

\subsection{Latar Belakang}

Petani yang melakukan usahatani padi seringkali mengalami permasalahan dan risiko. Menurut Pasaribu (2010), secara teknis kegiatan usaha disektor pertanian seperti usahatani padi akan selalu dihadapkan pada risiko ketidakpastian yang cukup tinggi. Risiko ketidakpastian tersebut meliputi tingkat kegagalan panen yang disebabkan oleh banjir, kekeringan serta serangan hama dan penyakit, disamping risiko ketidakpastian harga pasar. Ketidakpastian dan tingginya risiko ini sangat memungkinkan petani beralih mengusahakan komoditas lain yang mempunyai nilai ekonomi tinggi dengan risiko kegagalan yang lebih kecil. Hal ini dikhawatirkan akan berdampak terhadap stabilitas ketahanan pangan nasional, khususnya produksi, dan ketersediaan bahan pangan pokok beras.

Sejalan dengan upaya pemerintah Indonesia untuk memberikan perlindungan petani apabila terjadi kehilangan hasil akibat bencana alam dan serangan OPT maka pemerintah mengeluarkan Undang-Undang No 19 Tahun 2013 tentang Perlindungan dan Pemberdayaan Petani dengan menyelenggarakan program Asuransi Pertanian. Undang-Undang No 19 Tahun 2013 sah dilaksanakan pada tahun 2015 dengan adanya penerbitan Peraturan Menteri Pertanian No 40 Tahun 2015 tentang Fasilitasi Asuransi Pertanian yaitu Asuransi Usaha Tani Padi (AUTP).

Program AUTP sudah diberlakukan hampir di seluruh provinsi di Indonesia mulai tahun 2015. Perusahaan BUMN yang ditunjuk sebagai pelaksana program AUTP adalah PT Jasa Indonesia. Provinsi Bali juga merupakan daerah yang ikut serta dalam program AUTP sejak bulan Oktober. Kabupaten Tabanan merupakan salah satu dari enam kabupaten di Provinsi Bali yang mengikuti program AUTP sejak dimulai pada tahun 2015. Kabupaten Tabanan merupakan daerah yang paling banyak mengasuransikan lahan dan paling banyak mendapatkan klaim. Subak yang paling banyak mendapatkan klaim di Kabupaten Tabanan adalah Subak Cepik Desa Tajen Kecamatan Penebel yaitu Rp 180.000.000 dengan jumlah kerusakan lahan sebanyak 30 ha. Petani yang mendapatkan klaim terdiri dari 66 orang dengan kerusakan disebabkan oleh serangan tikus (PT Jasindo Cabang Denpasar, 2016).

Hasil penelitian dari Ambarawati, dkk (2016) menunjukkan bahwa program AUTP sangat bermanfaat untuk mengatasi risiko kegagalan panen padi. Petani peserta AUTP menikmati adanya subsidi pembayaran premi sebesar $80 \%$ dari total premi Rp 180.000/ha. $85 \%$ petani mengharapkan adanya subsidi penuh dari pemerintah sehingga petani tidak perlu membayar premi. Keinginan petani untuk membayar premi AUTP bisa dipengaruhi oleh beberapa faktor seperti luas lahan, umur, jenis kelamin, tingkat pendidikan, pengalaman usahatani padi, jumlah tanggungan keluarga petani, biaya usahatani padi dan kepuasan petani terhadap pelaksanaan program AUTP. Hal tersebut perlu untuk dikaji sejauh mana petani Subak Cepik menerima program Asuransi Usaha Tani Padi (AUTP) melalui seberapa kesediaan petani untuk membayar premi AUTP dan apakah ada kendala saat pelaksanaan program AUTP. 


\subsection{Rumusan Masalah}

Berdasarkan latar belakang di atas, maka masalah yang dapat dikemukakan dalam penelitian ini adalah :

1. Berapakah nilai Willingness to Pay atau kesediaan petani Subak Cepik, Desa Tajen, Kecamatan Penebel, Kabupaten Tabanan dalam membayar premi Asuransi Usaha Tani Padi (AUTP)?

2. Kendala-kendala apa yang terjadi dalam pelaksanaan Asuransi Usaha Tani Padi (AUTP) di Subak Cepik, Desa Tajen, Kecamatan Penebel, Kabupaten Tabanan bagi pihak petani maupun pihak PT Jasindo?

\subsection{Tujuan Penelitian}

Tujuan penelitian adalah :

1. Mengetahui Willingness to Pay atau kesediaan petani Subak Cepik, Desa Tajen, Kecamatan Penebel, Kabupaten Tabanan dalam membayar premi Asuransi Usaha Tani Padi (AUTP).

2. Mengetahui kendala-kendala apa yang terjadi dalam pelaksanaan Asuransi Usaha Tani Padi (AUTP) di Subak Cepik, Desa Tajen, Kecamatan Penebel, Kabupaten Tabanan bagi pihak petani maupun pihak PT Jasindo.

\subsection{Manfaat}

Manfaat dari penelitian ini adalah :

1. Pemerintah Daerah Kabupaten Tabanan, dapat dijadikan masukan dalam menentukan kebijakan pada sektor pertanian tanaman padi di Kabupaten Tabanan.

2. Penulis, dapat dijadikan penambah wawasan dalam aplikasi teori perkuliahan untuk diterapkan di lapangan.

3. Pihak lain, dapat dijadikan referensi dan informasi yang berkaitan dengan AUTP.

\subsection{Ruang Lingkup}

Penelitian ini menggunakan objek petani yang mengikuti program Asuransi Usaha Tani Padi (AUTP) di Subak Cepik, Desa Tajen, Kecamatan Penebel, Kabupaten Tabanan. Kajian yang diteliti menitikberatkan pada nilai Willingness to Pay (WTP) atau kesediaan dalam membayar premi AUTP dan kendala dalam proses pelaksanaan program AUTP bagi pihak petani dan PT Jasindo. Metode Contingent Valuated Method (CVM) digunakan untuk mencari nilai WTP. Metode deskriptif kualitatif digunakan untuk mencari kendala-kendala dalam pelaksanaan AUTP. Nilai WTP digunakan untuk mengetahui jumlah premi yang bersedia dibayar oleh petani di Subak Cepik. Nilai WTP yang didapat akan menghasilkan informasi mengenai seberapa besar penerimaan petani terhadap program AUTP yang dibuat oleh pemerintah Indonesia melalui UndangUndang No 19 Tahun 2013 tentang Perlindungan dan Pemberdayaan Petani. Penelitian 
ini juga menghasilkan kendala-kendala yang dihadapi selama pelaksanaan AUTP oleh pihak petani Subak Cepik dan PT Jasindo.

\section{Metode Penelitian}

\subsection{Lokasi Penelitian}

Lokasi penelitian dilaksanakan di Subak Cepik, Desa Tajen, Kecamatan Penebel, Kabupaten Tabanan. Pemilihan lokasi ini dilaksanakan dengan metode purposive yaitu metode penentuan lokasi yang dilakukan secara sengaja terhadap 66 petani yang menjadi peserta AUTP sejak tahun 2015 dan telah menerima klaim pada bulan April 2016. Lokasi penelitian ini dipilih karena Subak Cepik sudah pernah mengikuti program AUTP sejak program ini mulai dilaksanakan pada tahun 2015 dan memiliki total klaim asuransi paling banyak di Bali sebesar Rp 180.000.000/30 ha/MT.

\subsection{Jenis Data dan Sumber Data}

Jenis data dalam penelitian ini ada dua, yaitu kuantitatif dan kualitatif. Data kuantitatif yang digunakan dalam penelitian ini adalah biaya usahatani sebelum klaim, jumlah klaim petani, dan nilai WTP petani Subak Cepik terhadap pelaksanaan AUTP. Data kualitatif yang digunakan dalam penelitian ini mencakup : gambaran umum, masalah usahatani padi, risiko kegagalan panen yang pernah terjadi, dan kendala dalam pelaksanaan AUTP di Subak Cepik.

Sumber data dalam penelitian ini ada dua, yaitu primer dan sekunder. Data primer mencakup gambaran umum, usahatani padi, penyebab kegagalan panen, jumlah klaim, dan nilai kesediaan membayar premi AUTP. Data sekunder adalah data yang bersumber dari literatur atau publikasi yang berkaitan dengan penelitian.

\subsection{Metode Pengumpulan Data}

Metode pengumpulan data dalam penelitian ini menggunakan metode kuesioner, wawancara mendalam, observasi, studi kepustakaan, dan dokumentasi.

\subsection{Populasi, Sampel, dan Teknik Pengambilan Sampel}

Populasi dalam penelitian ini adalah petani Subak Cepik yang mengikuti program AUTP pada musim tanam Oktober 2015 - Maret 2016 dan telah mendapatkan klaim pada bulan April 2016 yaitu sebanyak 66 orang. Sampel yang dipilih berdasarkan hasil rumus slovin sebanyak 40 orang.

\subsection{Variabel dan Pengukuran Variabel}

Variabel-variabel yang akan dianalisis dalam penelitian ini adalah nilai Willingness to Pay (WTP) petani padi dan kendala dalam pelaksanaan AUTP di Subak Cepik. Data yang diperoleh, baik data primer maupun data sekunder akan diolah serta dianalisis secara kualitatif dan kuantitatif. Variabel nilai WTP petani mencakup indikator premi AUTP yaitu jumlah premi yang bersedia dibayarkan petani. Variabel 
kendala pelaksanaan AUTP mencakup dua indikator yaitu kendala petani dan kendala PT Jasindo.

\subsection{Batasan Operasional}

a. Asuransi Usaha Tani Padi (AUTP) adalah program asuransi dari pemerintah yang bertujuan untuk menekan risiko usaha tani padi.

b. Premi AUTP adalah sejumlah uang yang harus dibayarkan setiap 6 bulan yaitu sebanyak Rp 36.000/ha sebagai kewajiban dari tertanggung yaitu petani padi atas keikutsertaannya pada program AUTP.

c. Klaim AUTP adalah sebuah permintaan resmi kepada perusahaan asuransi untuk meminta pembayaran berdasarkan ketentuan perjanjian antara petani padi dengan pihak perusahaan asuransi yang mengurus mengenai AUTP.

d. Willingness to Pay (WTP) adalah kesediaan terhadap AUTP untuk mengeluarkan imbalan (uang) atas jasa yang diperolehnya (Rp/ha/MT).

e. Contingent Valuation Method (CVM) adalah salah satu metodologi berbasis survei untuk mengestimasi seberapa besar penilaian seorang/masyarakat terhadap barang, jasa, dan kenyamanan.

f. Kendala pelaksanaan AUTP adalah hambatan yang dihadapi saat proses kegiatan AUTP di Subak Cepik baik bagi petani maupun bagi PT Jasindo sebagai pelaksana program tersebut.

\subsection{Analisis Data}

Analisis data yang digunakan dalam penelitian ini adalah :

\subsubsection{Willingness to pay petani terhadap pelaksanaan AUTP}

\subsubsection{Membuat pasar hipotetik}

Dasar pembentukan pasar hipotetik dalam penelitian ini adalah risiko kegagalan panen padi akibat puso di Subak Cepik, Desa Tajen, Kecamatan Penebel, Kabupaten Tabanan. Diperlukan adanya antisipasi untuk membantu petani dalam mengatasi risiko kegagalan panen tersebut. Bentuk antisipasi ini adalah dengan mengikuti program AUTP. Tarif premi yang wajib dibayar petani peserta AUTP yaitu sebesar Rp 36.000/ha/MT dengan klaim yang didapat jika terjadi kerusakan adalah sebesar Rp 6.000.000/ha/MT. Petani Subak Cepik saat ini sudah banyak mendapatkan klaim dari AUTP. Bagaimana respon petani Subak Cepik jika ditanyakan berapa mereka bersedia membayar premi AUTP terlepas dari kebijakan program AUTP untuk membayar premi Rp 36.000/ha/MT.

\subsubsection{Mendapatkan Penawaran Besarnya Nilai WTP}

Penawaran mengenai besarnya nilai WTP diperoleh melalui survei dengan wawancara langsung. Teknik yang digunakan untuk mendapatkan nilai penawaran adalah Open-ended Question. Teknik ini dilakukan dengan memberikan pertanyaan terbuka kepada petani Subak Cepik, Desa Tajen, Kecamatan Penebel, Kabupaten Tabanan tentang WTP premi AUTP maksimum yang bersedia mereka bayarkan. 


\subsubsection{Menghitung dugaan rataan willingness to pay (EWTP)}

$$
\mathrm{EWTP}=\sum_{i=1}^{n} \mathrm{WiPfi}
$$

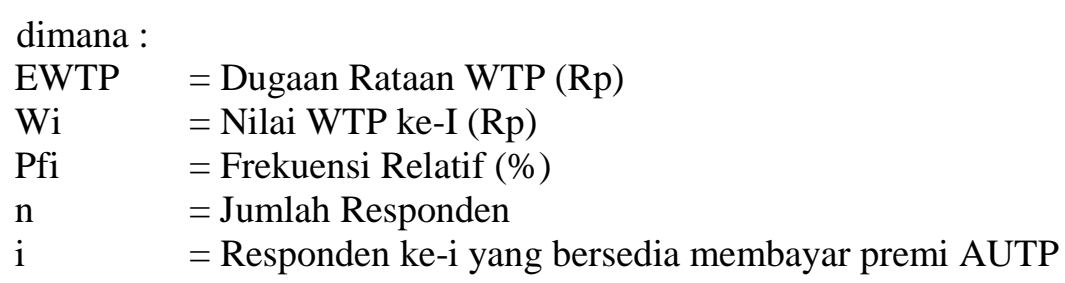

\subsubsection{Menentukan total willingness to pay (TWTP)}

$$
\mathrm{TWTP}=\sum_{i=i}^{n} W T P i\left(\frac{n i}{N}\right) P
$$

dimana :

TWTP $=$ Total WTP

WTPi = WTP individu sampel ke-i

ni $\quad=$ Jumlah sampel ke-i yang bersedia membayar sebesar WTP

$\mathrm{N} \quad=$ Jumlah sampel

$\mathrm{P} \quad \quad=$ Jumlah populasi

$\mathrm{i}=$ = Responden ke i yang bersedia membayar premi AUTP

\subsubsection{Mengevaluasi penggunaan CVM}

Tahap evaluasi CVM menilai sejauhmana penggunaan CVM telah berhasil. Tahap ini memerlukan pendekatan seberapa besar tingkat keberhasilan dalam pengaplikasian CVM. Pengevaluasi pelaksanaan model CVM dapat dilihat dari tingkat keandalan (reability) fungsi WTP yang ditunjukkan oleh nilai koefisien determinasi $\left(\mathrm{R}^{2}\right)$ dari model OLS (Ordinary Least Square). Pelaksanaan CVM dianggap berhasil apabila nilai $\mathrm{R}^{2}$ sama atau lebih dari 0,150 .

\subsubsection{Analisis deskriptif kualitatif}

Penelitian deskriptif kualitatif ditujukan untuk mendeskripsikan dan menggambarkan fenomena-fenomena yang ada, baik bersifat alamiah maupun rekayasa manusia yang lebih memperhatikan mengenai karakteristik, kualitas dan keterkaitan antar kegiatan. Penelitian deskriptif tidak memberikan perlakuan, manipulasi atau pengubahan pada variabel-variabel yang diteliti, melainkan menggambarkan suatu kondisi yang apa adanya. 


\section{Hasil dan Pembahasan}

\subsection{Willingness to pay (WTP) petani terhadap pelaksanaan AUTP}

Berdasarkan metode CVM diperoleh WTP dari 40 sampel di Subak Cepik Desa Tajen Penebel Tabanan. Hasil pelaksanaan CVM untuk memperoleh nilai WTP petani adalah sebagai berikut :

\subsubsection{Pembentukan pasar hipotetik}

Subak Cepik sudah mendapatkan klaim dari AUTP terhitung untuk klaim pertama yang diterima pada bulan April 2016 sebesar Rp 180.000.000 dari 30 ha kerusakan lahan padi. Premi yang dibayar sudah ditanggung oleh pemerintah $80 \%$ dan petani hanya membayar sebanyak 20\%. Petani yang telah memperoleh gambaran tentang situasi pasar hipotetik pelaksanaan AUTP, kemudian diminta untuk memberikan respon kesediaan membayar premi AUTP secara pribadi, terlepas dari kebijakan premi Rp 36.000/ha/MT pada program AUTP.

\subsubsection{Perolehan nilai penawaran willingness to pay}

Berdasarkan hasil perhitungan diperoleh 13 macam nilai premi AUTP yang bersedia dibayar oleh petani. Nilai terkecil adalah Rp 100/ha dan yang tertinggi adalah $\operatorname{Rp} 75.000 /$ ha.

\subsubsection{Dugaan rataan willingness to pay}

Dugaan nilai rata-rata WTP responden diperoleh berdasarkan data distribusi WTP responden dan menggunakan rumus. Distribusi nilai WTP responden dapat dilihat pada Tabel 1.

Tabel 1.

Distribusi WTP Petani terhadap Pelaksanaan AUTP di Subak Cepik, Desa Tajen Kecamatan Penebel, Tabanan

\begin{tabular}{|c|c|c|c|c|}
\hline \multirow{2}{*}{ No } & \multirow{2}{*}{$\begin{array}{l}\text { Kelas WTP } \\
\text { (Rp/ha/MT) }\end{array}$} & \multicolumn{2}{|c|}{ Frekuensi } & \multirow{2}{*}{$\begin{array}{c}\text { EWTP } \\
(\mathrm{Rp} / \mathrm{ha} / \mathrm{MT})\end{array}$} \\
\hline & & (orang) & $(\%)$ & \\
\hline 1 & 100 & 1 & 2,5 & 2,5 \\
\hline 2 & 5.000 & 1 & 2,5 & 125 \\
\hline 3 & 10.000 & 1 & 2,5 & 250 \\
\hline 4 & 15.000 & 5 & 12,5 & 1.875 \\
\hline 5 & 18.000 & 2 & 5 & 900 \\
\hline 6 & 25.000 & 4 & 10 & 2.500 \\
\hline 7 & 30.000 & 1 & 2,5 & 750 \\
\hline 8 & 35.000 & 1 & 2,5 & 875 \\
\hline 9 & 36.000 & 18 & 45 & 16.200 \\
\hline 10 & 40.000 & 2 & 5 & 2.000 \\
\hline 11 & 45.000 & 2 & 5 & 2.250 \\
\hline 12 & 50.000 & 1 & 2,5 & 1.250 \\
\hline 13 & 75.000 & 1 & 2,5 & 1.875 \\
\hline & Total & 40 & 100 & 30.853 \\
\hline
\end{tabular}

Sumber : Data primer diolah (2017). 
Berdasarkan Tabel 1 dapat diketahui bahwa persentase terbesar WTP responden berada pada kelas Rp 36.000. Dugaan nilai rata-rata WTP (EWTP) sebesar Rp 30.853/ha/MT yaitu sebesar $86 \%$ dari yang sudah dibayar petani. Nilai tersebut berada di bawah nilai premi yang berlaku saat ini yaitu rata-rata sebesar Rp 36.000/ha/MT. Hal ini menunjukkan bahwa petani masih menginginkan subsidi dari pemerintah.

\subsubsection{Total willingness to pay}

Nilai total (TWTP) responden dihitung berdasarkan data distribusi WTP responden dan dengan menggunakan rumus (Christiarini, 2011). Hasil perhitungan total WTP dapat dilihat pada Tabel 2.

Tabel 2.

TWTP Petani Subak Cepik terhadap Pelaksanaan AUTP

\begin{tabular}{ccccr}
\hline No & $\begin{array}{r}\text { Kelas WTP } \\
\text { (Rp/ha/MT) }\end{array}$ & Sampel (orang) & $\begin{array}{r}\text { Populasi Petani } \\
\text { (orang) }\end{array}$ & $\begin{array}{c}\text { TWTP } \\
\text { (Rp/MT) }\end{array}$ \\
\hline 1 & 100 & 1 & 5,6 & 560 \\
2 & 5.000 & 1 & 5,6 & 28.000 \\
3 & 10.000 & 1 & 5,6 & 56.000 \\
4 & 15.000 & 5 & 28 & 420.000 \\
5 & 18.000 & 2 & 11,2 & 201.600 \\
6 & 25.000 & 4 & 22,4 & 560.000 \\
7 & 30.000 & 1 & 5,6 & 168.000 \\
8 & 35.000 & 1 & 5,6 & 196.000 \\
9 & 36.000 & 18 & 100,8 & 3.628 .800 \\
10 & 40.000 & 2 & 11,2 & 448.000 \\
11 & 45.000 & 2 & 11,2 & 504.000 \\
12 & 50.000 & 1 & 5,6 & 280.000 \\
13 & 75.000 & 1 & 5,6 & 420.000 \\
\hline Total & 384.100 & 40 & 224 & 6.910 .960 \\
\hline Sur
\end{tabular}

Sumber : Data primer diolah (2017).

Tabel 2 menunjukkan nilai total WTP responden sebesar Rp 6.910.960/MT. Populasi petani merupakan jumlah petani Subak Cepik yang mengikuti AUTP sebanyak 224 orang. Total WTP petani berada dibawah total premi yang berlaku saat ini yaitu Rp 8.064.000/MT. Hasil ini menunjukkan total premi AUTP yang dikeluarkan responden sebanyak $85,70 \%$ dari yang sudah dibayarkan.

\subsubsection{Evaluasi penggunaan CVM}

Penggunaan CVM dalam penelitian ini di evaluasi dengan melihat nilai $\mathrm{R}^{2}$ (koefisien determinasi) yang diperoleh dari hasil analisis regresi linier berganda. Variabel yang digunakan untuk mencari nilai $\mathrm{R}^{2}$ diantaranya luas lahan, jenis kelamin, umur, pengalaman usahatani padi, tingkat pendidikan, jumlah tanggungan keluarga petani, tingkat kepuasan dan biaya usahatani padi sebelum klaim serta jumlah klaim petani. Berdasarkan hasil analisis fungsi WTP diperoleh nilai $\mathrm{R}^{2}$ sebesar 0,163 atau $16,3 \%$. Nilai $\mathrm{R}^{2}$ tersebut menunjukkan bahwa hasil pelaksanaan CVM dalam penelitian ini dapat diyakini kebenarannya atau keandalannya. 


\subsection{Kendala-Kendala Pelaksanaan AUTP bagi Pihak Petani Subak Cepik dan PT Jasindo}

Pelaksanaan Asuransi Usaha Tani Padi baik dari pihak petani sebagai peserta AUTP maupun PT Jasindo sebagai penyelenggara AUTP memiliki beberapa kendala. Adapun kendala dari petani dalam mengikuti pelaksanaan AUTP adalah sebagai berikut :

a. Kendala petani ada tiga diantaranya dalam proses sosialisasi AUTP, proses pembayaran premi AUTP dan pemeriksaan lahan petani yang kurang transparan dalam proses pengajuan klaim.

b. Kendala PT Jasindo mencakup kesulitan mengajak petani dalam mengikuti sosialisasi AUTP dan saat pendaftaran peserta AUTP yaitu prosedur keikutsertaan program AUTP.

\section{Kesimpulan dan Saran}

\subsection{Kesimpulan}

Kesimpulan dalam penelitian ini adalah sebagai berikut :

1. Besarnya iuran premi AUTP yang ditetapkan melalui pendekatan Willingness to Pay (WTP) petani adalah Rp 30.853/ha/MT, sedangkan iuran premi AUTP yang berlaku saat ini adalah Rp 36.000/ha/MT, sehingga dapat dikatakan bahwa petani responden menginginkan iuran premi AUTP diturunkan.

2. Kendala-kendala yang dihadapi saat pelaksanaan program AUTP di Subak Cepik yaitu sebagai berikut :

a. Bagi petani, kendala yang paling banyak yaitu pada proses sosialisasi AUTP karena petani kurang mendapat sosialisasi tentang pelaksanaan AUTP

b. Bagi PT Jasindo, terdapat kendala mengenai proses sosialisasi AUTP dan saat pendaftaran peserta AUTP.

\subsection{Saran}

1. Perlu adanya sinergis antara PT Jasindo dan petani dalam melakukan program AUTP agar program ini bisa dirasakan petani secara baik yaitu dengan cara sebagai berikut :

a. PT Jasindo lebih memperbanyak sosialisasi program AUTP dan melakukan proses pemeriksaan lahan padi petani dengan lebih transparan.

b. Petani lebih aktif menanyakan hal-hal yang berkaitan dengan program AUTP secara lebih menyeluruh kepada beberapa pihak baik itu dari PT Jasindo maupun dari PPL setempat.

2. Pihak pemerintah sebaiknya dapat menetapkan iuran premi AUTP yang berdasarkan hasil Willingness to Pay (WTP) petani seperti yang dilakukan dalam penelitian ini sehingga bisa sesuai dengan keinginan petani dan tidak memberatkan petani.

3. Diharapkan untuk penelitian berikutnya tentang WTP untuk jenis atau tingkat kerusakan yang lain seperti serangan OPT selain hama tikus.

\subsection{Ucapan Terima Kasih}

Penulis mengucapkan terima kasih kepada pihak yang telah mendukung terlaksananya penelitian ini yaitu kepada petani Subak Cepik dan Pengurus Desa Tajen 
Kecamatan Penebel, Kabupaten Tabanan, PT Jasindo Cabang Denpasar, Dinas Pertanian Provinsi Bali, dan BPS Provinsi Bali. Ucapan terimakasih juga disampaikan kepada dosen pembimbing, keluarga, teman-teman dan semua pihak yang tidak dapat disebutkan satu persatu. Semoga penelitian ini bermanfaat sebagaimana mestinya.

\section{Daftar Puskata}

Ambarawati, I.G.A.A., Wijaya, I.M.A.S dan Budiasa,. 2016. Mitigasi Risiko Produksi Padi Melalui Asuransi Pertanian di Provinsi Bali. Laporan Akhir Hibah Penelitian Unggulan Udayana. Lembaga Penelitian dan Pengabdian kepada Masyarakat UNUD.

Arifah, F.N. 2008. Analisis Willingness to Pay Petani terhadap Peningkatan Pelayanan Irigasi Melalui Rehabilitasi Jaringan Irigasi (Studi Kasus: Daerah CidasaneEmpang, Desa Pasir Gaok, Kecamatan Rancabungur, Kabupaten Bogor-Jawa Barat). Skripsi. Fakultas Pertanian Institut Pertanian Bogor. https://core.ac.uk/download/pdf/32371606.pdf. Diakses pada tanggal 15 Januari 2017.

Badan Pusat Statistik. 2012. Statistik Indonesia.. https://www.bps.go.id. Diakses pada tanggal 11 September 2017.

Christiarini. D. 2011. Analisis Rencana Pemberlakuan Electronic Road Pricing untuk Mengurangi Polusi Lingkungan (Kasus Jalan Jenderal Sudirman, Jakarta Pusat). https://core.ac.uk/download/pdf/32377622.pdf. Diakses pada tanggal 11 Maret 2017.

Direktorat Jenderal Prasarana dan Sarana Pertanian. 2015. Rencana Strategis Ditjen PSP Periode 2015-2019. https://www.psp.pertanian.go,id/index.php/page/profil. Diakses pada tanggal 8 Maret 2017.

PT Jasindo Cabang Denpasar. 2017. Pelaksanaan Program Asuransi Usaha Tani Padi (AUTP) di Provinsi Bali.

Pasaribu, S. 2010. Pengembangan Asuransi Usahatani Padi untuk menanggulangi Risiko Kerugian 75\% Akibat Banjir, Kekeringan dan Hama Penyakit. Usulan Penelitian. Pusat Analisis Sosial Ekonomi dan Kebijakan Pertanian Kementrian Pertanian. http://pse.litbang.pertanian.go.id/ind/pdffiles/MAKPROF.SH.pdf. Diakses pada tanggal 08 Maret 2017.

Pasaribu. S. 2015. Penerapan Asuransi Pertanian di Indonesia. https://www.litbang.pertanian.go.id/buku/reformasi-kebijakan-menuju/BAB-IV9.pdf. Diakses pada tanggal 15 Januari 2017.

Prasmatiwi, F.E., Irham, I, Suryantini, A dan Jamhari. 2017. Kesediaan Membayar Petani Kopi untuk Perbaikan Lingkungan. E-Journal Ekonomi Pembangunan. Fakultas Pertanian Universitas Lampung dan Fakultas Pertanian Universitas Gadjah Mada Yogyakarta. https://publikasiilmiah.ums.ac.id/handle/11617/1318. Diakses pada tanggal 18 Januari 2017.

Rethiandy, dkk. 2015. Analisis Risiko Usahatani Padi di Kecamatan Karanganyar Kabupaten Karangayar. Skripsi. Fakultas Pertanian Universitas Sebelas Maret Surakarta.http://agribisnis.fp.uns.ac.id/wpcontent/uploads/2015/01/JURNAL6.pd f.Diakses pada tanggal 07 Maret 2017. 